\title{
A method to define the spatial stations location in a carsharing system in São Paulo -Brazil
}

\author{
M. O. Lage ${ }^{1, *}$, C. A. S. Machado ${ }^{1}$, F. Berssaneti ${ }^{2}$, J. A. Quintanilha ${ }^{1}$ \\ ${ }^{1}$ Dept. of Transportation Engineering, Polytechnic School, University of São Paulo, Avenida Professor Almeida Prado, Travessa 2, \\ n. 83, São Paulo, Brazil - mariana_lage@usp.br, claudia.machado@usp.br, jaquinta@usp.br \\ ${ }^{2}$ Dept. of Production Engineering, Polytechnic School, University of São Paulo, Avenida Professor Luciano Gualberto, n. 1380, São \\ Paulo, Brazil - fernando.berssaneti@usp.br
}

Commission VI, WG VI/4

KEY WORDS: Transportation Systems, Spatial Analysis, Carsharing Station Location.

\begin{abstract}
:
Sharing mobility systems have become part of a sociodemographic trend that has pushed shared modes from the fringe to the mainstream of the transportation systems. Carsharing is a mode of shared transport, where a service is offered in which several people share the access and use of a set of vehicles. This is a relatively new mode of urban transport, which gives users access for short periods of rental, thus providing the benefits of using private vehicles, while avoiding the inherent property charges of a vehicle. The objective of the article searches for the identification and selection of preferred areas in the São Paulo City (Brazil) to implement a prototype of a carsharing system. The adopted methodology of demand analysis identifies the spatial patterns of the intervening variables of socioeconomic information, transportation and land use, in order to understand the current panorama of the demand for transport in São Paulo. The analysis made it possible to identify and select preferred areas in São Paulo for the implementation of a prototype. The study indicated the most favorable places to receive the service stations to operate a carsharing system.
\end{abstract}

\section{INTRODUCTION}

Sharing mobility systems have become part of a sociodemographic trend that has pushed shared modes from the fringe to the mainstream of the transportation systems (Shaheen and Cohen, 2018).

Sharing mobility is the shared use of a vehicle (car, bicycle, scooter, van or other travel mode). It is an innovative transportation strategy that enables users to have short-term access to a transportation mode on an as-needed basis, and can increase multimodality, reduce vehicle ownership and vehicle miles/kilometers traveled (VMT/VKT) (in some circumstances), and provides new ways to access goods and services (Shaheen et al., 2016; Shaheen and Cohen, 2018).

The last decade witnessed the exponential growth and dispersion of sharing mobility worldwide, with millions of users, who probably considered private vehicle ownership, deciding to share cars, bicycles and other vehicles in large and small cities across all continents (Dowling et al., 2018).

The evolution of vehicle sharing underwent its initial entry into the market as a period of experimentation (1994 to mid-2002) for market growth and diversification (mid-2002 to the end of 2007) for commercial mainstreaming (end of 2007 to the present). These developments include increased competition, new competitors on the market, consolidation of carsharing programs, increased market diversification, capital investment, technological advancement and increased collaboration between urban transport system operators. Continued growth and competition are foreseen. Increasing the costs associated with motor vehicle ownership and raising awareness about climate change are likely to facilitate such expansion (Shaheen et al., 2009). In this sense, Dowling et al. (2018) affirm that in bringing the example of vehicle sharing to geographical understanding of sharing, we are able to point to understandings of collaboration and individualism beyond the economic aspect, that is, to cultivate the social and environmental perspective of sharing.

According to Fleury et al. (2017) another advantage of vehicle sharing is that it minimizes the total number of vehicles needed. It is estimated that a shared car can replace between one and 6.5 personal vehicles and, moreover, tends to decrease the frequency of trips carried out by impulse, meaning the Carsharing not only makes people more aware of the cost per trip, but also demands that each trip be planned. Namazu et al. (2018) complement this view by stating that the supply of a variety of vehicles, which are often newer and more fuelefficient or propulsion technology (in the case of electric or hybrid vehicles) compared to typical private vehicles, can motivate the optimization of the size and characteristics of the vehicle, depending on the purposes of the trip.

This article seeks to identify and select preferred areas in the city of São Paulo to implement a prototype of a carsharing system of the Carsharing type. The study will indicate, from a space database that includes the location of a dealership's stores in the city of São Paulo, Brazil, which are the most favorable places to receive the service stations of carsharing.

\section{CARSHARING}

Carsharing is a mode of shared transport, where a service is offered in which several people share the access and use of a set of vehicles. This is a relatively new mode of urban transport, which gives users access to a fleet of shared vehicles for short periods of rental, thus providing the benefits of using private vehicles, while avoiding charges (Shaheen et al., 1998;

\footnotetext{
* Corresponding author
} 
Shaheen, 1999; Schaefers, 2013; Namazu and Dowlatabadi, 2018).

In recent years, the growth of vehicle sharing services as a new sustainable means of transportation has led to the shift from private mobility based on the ownership of the good (vehicle) to the use of the service. The basic idea of carsharing is quite simple: to share the use of a fleet of vehicles between members / users of the system to make trips according to the individual demand of each one. The fleet (economic asset) belongs to a company that operates the system (Ferrero et al., 2018).

There are three carsharing modalities: station-based round-trip, station-based one-way and free-floating one-way.

In station-base round-trip modality (see Figure 1) available vehicles are stationed in pick-up stations, which are parking lots defined by the service provider or local administration and the journey must start and end at the same station. Thus, this operational model does not consider any intermediate stops that the user can plan for personal needs. The set of parking lots (stations) is predefined (Ferrero et al., 2018).

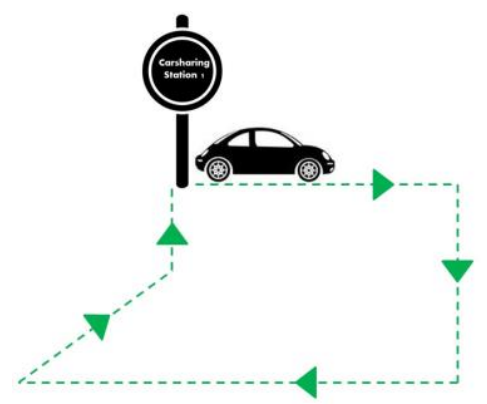

Figure 1. Carsharing station-based round-trip (Source: Authors)

The station-based one-way modality is similar to the previous one, but in the unidirectional case, the station where the trip ends may be different from the station where it started (see Figure 2). The set of parking lots (stations) is predefined (Ferrero et al., 2018).

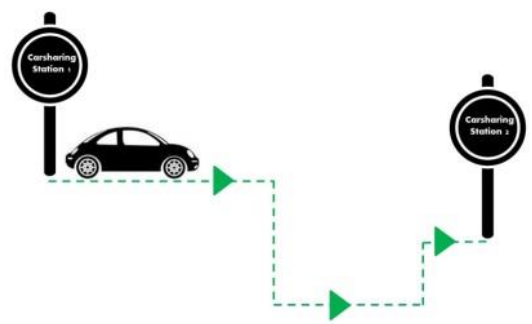

Figure 2. Carsharing station-based one-way (Source: Authors)

And the last one known as free-floating one-way, the vehicles are freely parked in public spaces within the operating area (the area serviced by the sharing company), and the journey can begin and end at any point in this area. (Figure 3) (Ferrero et al., 2018).

An important aspect to realize is how technology is shaping mobility and raising new demands for socialization and identity building. Information technology does not restrict access to (social) spaces, but it generates new ways of managing communication and mobility (Tully and Alfaraz, 2017). The amenities provided by "digital mobility", i.e. the ease of accessing a means of transport or vehicle (e. g requesting a ridesharing vehicle or making a reservation in the carsharing system), selecting the best route, monitoring congestion levels in real time, monitoring travel times, controlling the amounts to be paid, etc. are advantages that, especially, younger users seek when choosing a means of transportation to carry out their daily commutes. It is the optimization of the time, comfort and cost of the user. And in this context, carsharing systems have a lot to offer.

In the current study the carsharing modality adopted was station-based one-way.

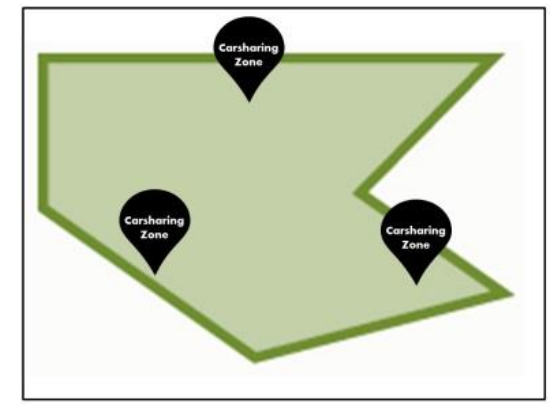

Figure 3. Carsharing free-floating one-way (Source: Authors)

\section{DATA AND METHOD}

This study considered the following public and free databases, which are available in tabular and vector formats: origin/destination survey of São Paulo City (Companhia do Metropolitano de São Paulo - METRÔ, 2007), health units (Prefeitura de São Paulo - Geosampa, 2015), leisure, sports and cultural spaces (Prefeitura de São Paulo - Geosampa, 2015), land use map (Prefeitura de São Paulo - Geosampa, 2015), road network (Centro de Estudos da Metrópole - CEM, 2018), São Paulo City districts (Prefeitura de São Paulo, 2011), and transport infrastructure (Prefeitura de São Paulo - Geosampa, 2015).

In order to understand the current panorama of the transport demand in the city, for each district (official administrative division of the Municipality of São Paulo); socioeconomic, transportation and land use information were collected from the database above described.

The adopted methodology for transport demand analysis identified spatial patterns of these intervening variables. The potentialities of the spatial analysis tools for the characterization of transport demand are vast, fast and very didactic, since they allow the visualization of the information in thematic maps that enables a simple, direct and precise interpretation.

It is important to highlight the agility that geotechnologies provide for these types of studies, being able to manipulate and analyze large volumes of data. With few actions can be generated diverse maps, containing a wide range of useful information to planners, administrators and managers of the transportation systems of large urban centers, as exemplified in this paper through the case study for the implementation of a system of carsharing in the Municipality of Sao Paulo.

After the collection, compatibility and spatialization of the data, performed in open source Geographic Information System (GIS) software (QGIS), the analysis was carried out to investigate which districts have the largest amount of entities such as train/subway stations, hotels, shopping malls, leisure and cultural facilities, and so on, which have the potential to generate trips, and consequently transport demand.

For the purpose of identify which districts would be the best choices to host carsharing service stations; a methodology has been developed to prioritize the most relevant information for the implementation of this transportation mode. A prioritization matrix based on weights (from 1 to 3 ) was developed to score 
the information, according to three hypothetical scenarios, alternating the importance among the information classes. In the first scenario the transportation system data (accessibility) was prioritized (with the maximum weight); in scenario 2 the priority was the flow of people (number of trips generated); and in the last scenario the land use data were assigned the maximum value weight, prioritizing the residential areas (trip origins) and the commercial and service areas (trip destinations).

In this paper, we also identify the user profile of carsharing as young people, high income user with high level of education. In addition, it has identified where the user's priority destinations are, such as workplaces (commerce and service), leisure facilities, among others, and their preferential transportation mode (motorized or non-motorized).

\section{RESULTS}

Figure 4 indicates the districts which are most likely to find the user of carsharing, according to the user profile defined in the analysis. It consists of a group of districts located in the Midwest region of the São Paulo City. Some demographic characteristics of this area: a large number of young adults, with high income and high education level.

It is also possible to identify, through the available data, the potential destinations to this target user. Figure 5 shows that these preferred trip destinations are in the districts that have the most important attractive activities for the potential usage of the carsharing system, such as leisure, sports and cultural facilities, educational establishments, health care units, restaurants, supermarkets and hotels.

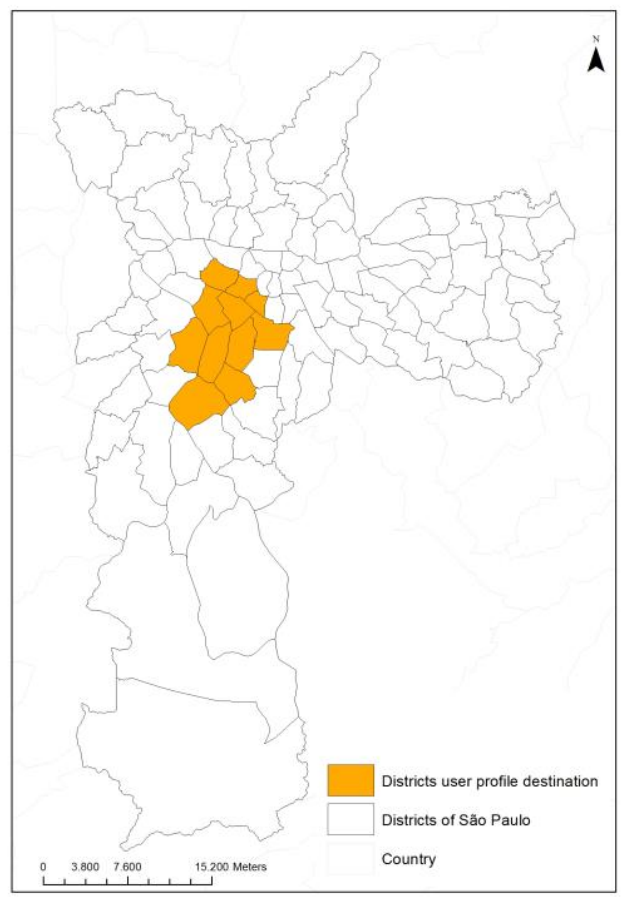

Figure 4. Preferential districts of origin according to user's profile of carsharing (Source: Authors)

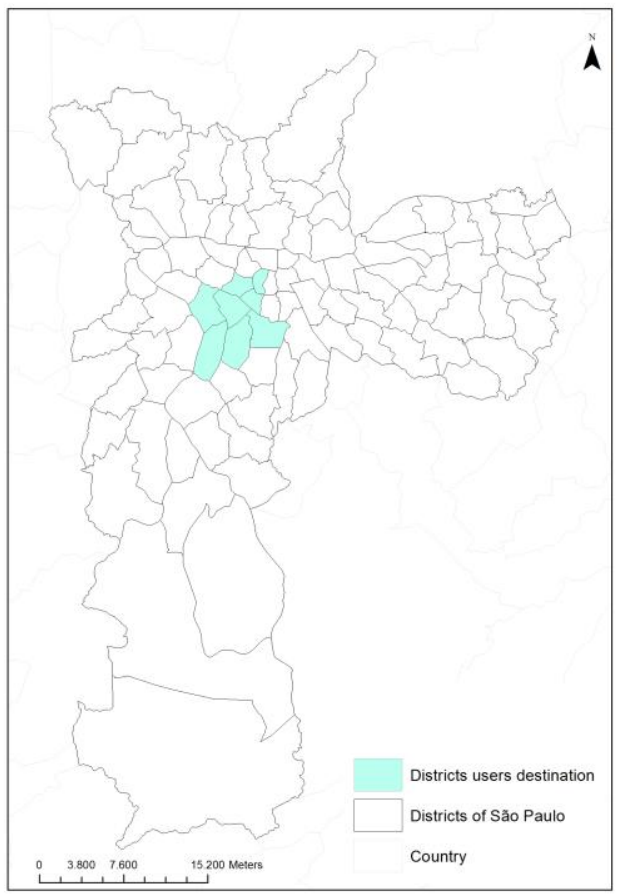

Figure 5. Preferred target districts according to the classes of variables relevant to the carsharing system (Source: Authors)

The following maps illustrate the preferred target districts (trips destinations, as can be seen in Figure 5) and the proportion of trips made by different transportation modes. Four transportation means were selected: taxi (Figure 6), private car (Figure 7), bicycle (Figure 8), and by foot (Figure 9). The larger the symbol represented in the map, the greater the amount of trips generated with this transportation mode.

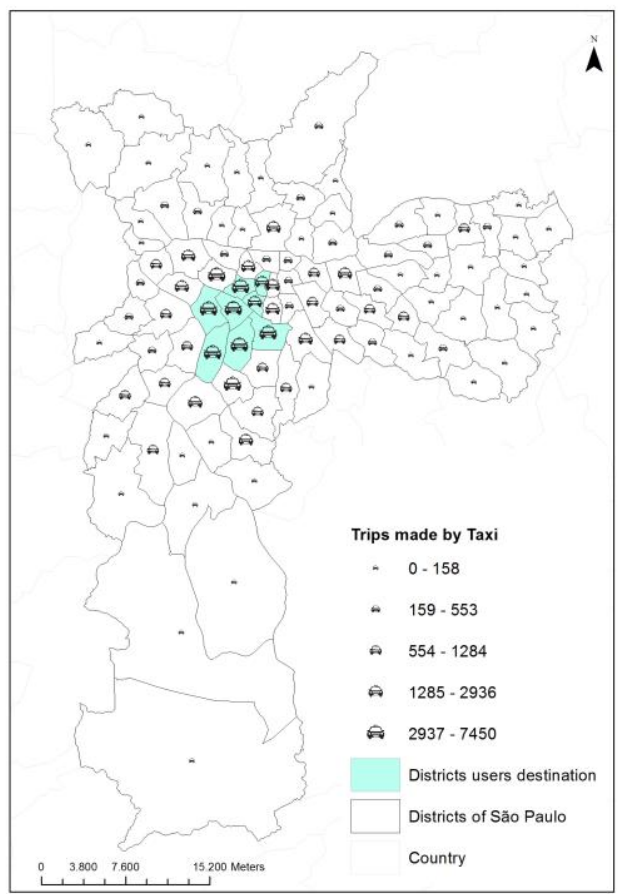

Figure 6. Number of trips: taxi (Source: Authors) 


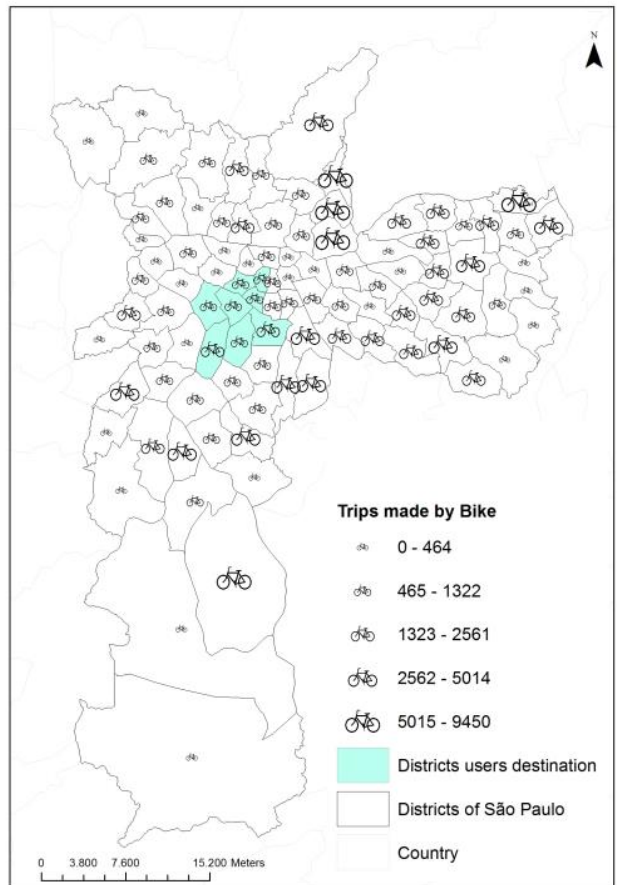

Figure 8. Number of trips: bicycle (Source: Authors)

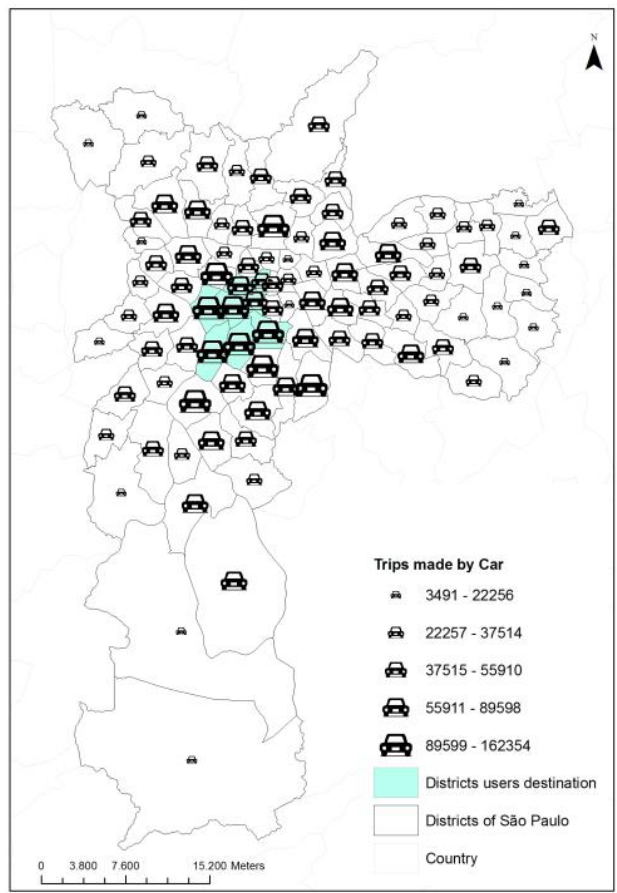

Figure 7. Number of trips: private car (Source: Authors)

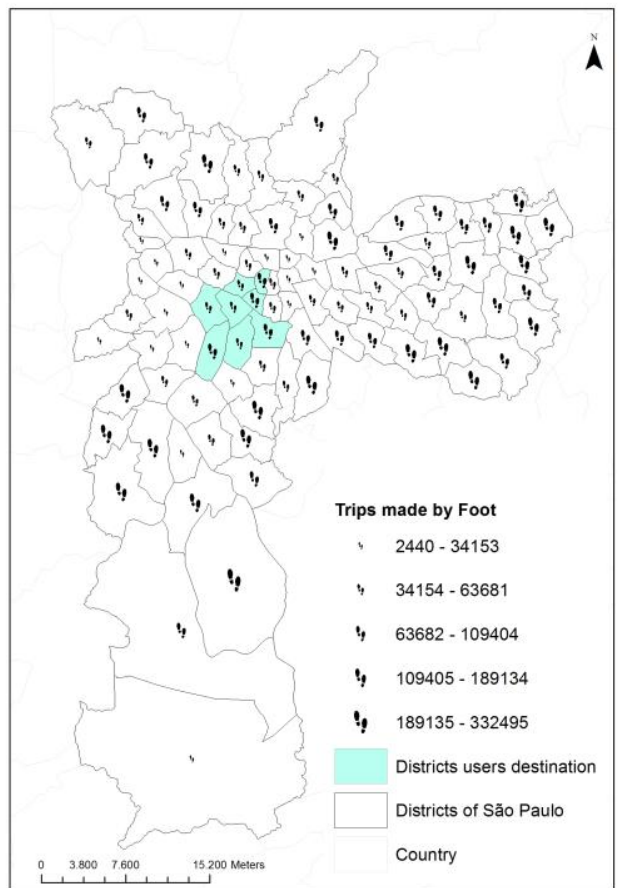

Figure 9. Number of trips: by foot (Source: Authors)

As described in the previous section, were considered three analysis scenarios: the first one prioritizing the data of the transportation system (accessibility), the second one prioritizing the flow of people (number of generated trips), and last one prioritizing the land use data (trip origins/destinations). Figures 10 to 12 show the evaluation of the three scenarios. The candidate districts to receive the carsharing stations are at the intersection of the three scenarios (Figure 13). 


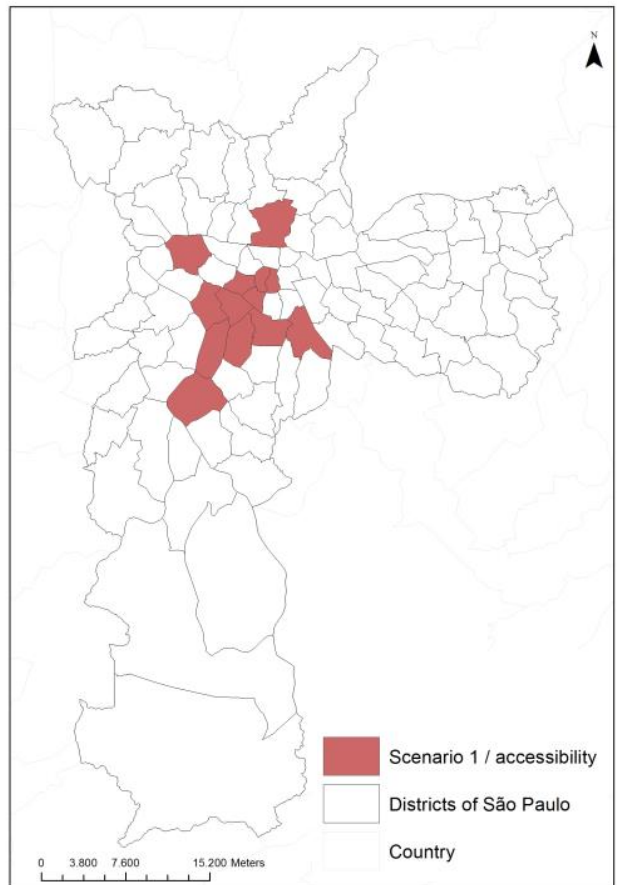

Figure 10. Preferential districts for carsharing system implementation according to scenario 1. (Source: Authors)

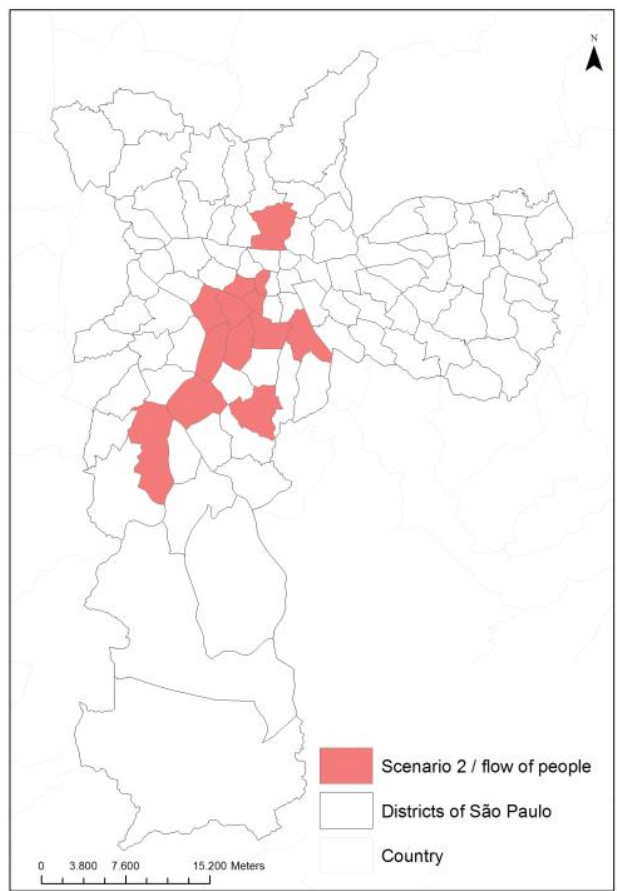

Figure 11. Preferential districts for carsharing system implementation according to scenario 2. (Source: Authors)

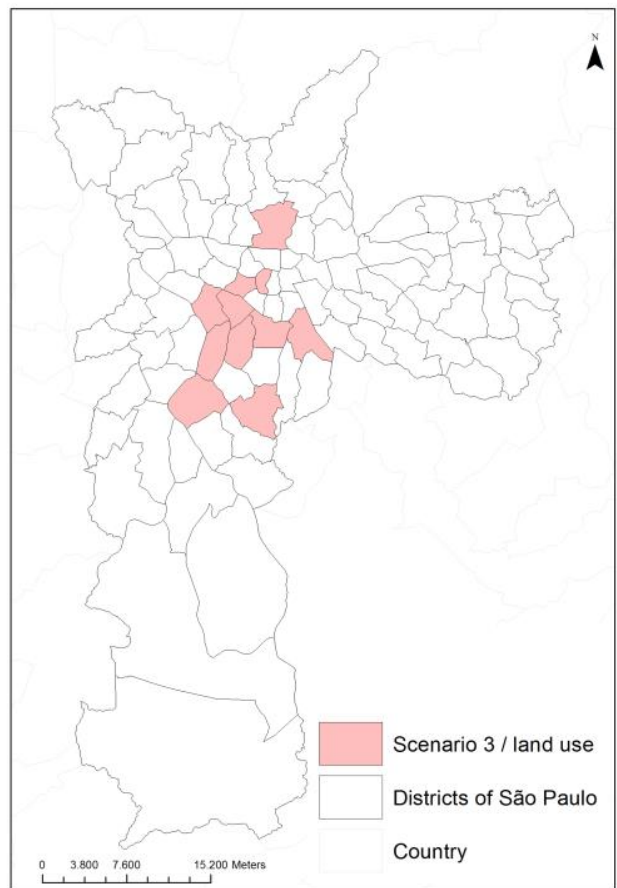

Figure 12. Preferential districts for carsharing system implementation according to scenario 3. (Source: Authors)

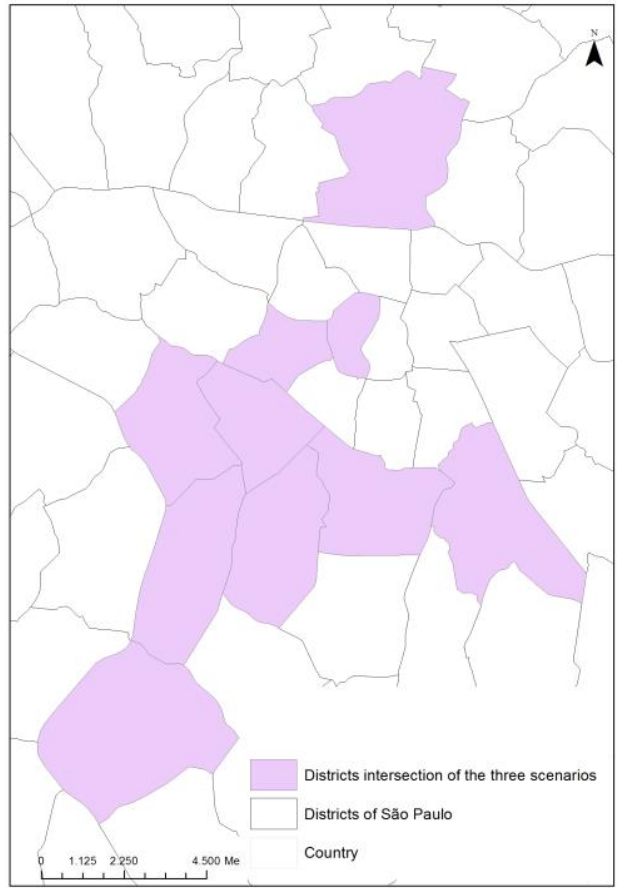

Figure 13. Intersection of the three scenarios: candidate districts to receive the carsharing stations. (Source: Authors) 


\section{CONCLUSIONS}

Carsharing services facilitate access to vehicles and discourage the purchase of such goods, in cases where the car is used in a short-term on an as-needed basis. This type of service can produce positive changes to the city, because sharing cars helps reduce the number of vehicles purchased and outstanding, reducing congestion and improving air quality, which today represents an important improvement factor for urban centers.

By the spatial data analysis of available free databases, the method yields the districts in the city of São Paulo (Brazil) more favorable for the implementation of a prototype of a carsharing system.

The analysis made it possible to define the profile of the potential users of the carsharing system. Once the profile of the target audience is known, socioeconomic and spatial data have allowed the mapping of these users, i.e. where they are and where they want/need to go. Once the most probable origins and destinations for the carsharing mode were known, the database used in this study made it possible to identify areas of the city of São Paulo (districts) that are candidates to receive the carsharing stations and operate the system.

In a first phase of operation, a physical station is required for familiarity with the system (by users and also by the operator), fleet dimensioning, number of employees, etc. Eventually, with the expansion of the service, there may be a migration to a selfservice model (total or partial) through a digital platform, with withdrawal / delivery stations and inspection of vehicles at different addresses, for example through an agreement established with private car parking networks, shopping malls, airports, etc.

\section{ACKNOWLEDGEMENTS}

The authors would like to acknowledge the Foundation for the Technological Development of Engineering (FDTE); Polytechnic School of the University of São Paulo, and the National Research Council - CNPq.

\section{REFERENCES}

Centro de Estudos da Metrópole (CEM), 2018.

http://web.fflch.usp.br/centrodametropole/Softwares (25

February 2018).

Companhia do Metropolitano de São Paulo (Metrô), 2007.

Pesquisa Origem e Destino.

https://transparencia.metrosp.com.br/dataset/pesquisa-origem-edestino (25 February 2018).

Dowling, R., Maalsen, S., Kent, J. L., 2018. Sharing as sociomaterial practice: Car sharing and the material reconstitution of automobility. Geoforum, 88, pp. 10-16.

Ferrero, F., Perboli, G., Rosano, M., Vesco, A., 2018. Carsharing services: An annotated review. Sustainable Cities and Society, 37, pp. 501-518.

Fleury, S., Tom, A., Jamet, E. Colas-Maheux, E., 2017. What drives corporate carsharing acceptance? A French case study. Transportation Research Part F: Traffic Psychology and Behaviour, 45, pp. 218-227.

Namazu, M., Dowlatabadi, H., 2018. Vehicle ownership reduction: A comparison of one-way and two-way carsharing systems. Transport Policy, 64, pp. 38-50.
Namazu, M., Mackenzie, D., Zerriffi, H., Dowlatabadi, H., 2018. Is carsharing for everyone? Understanding the diffusion of carsharing services. Transport Policy, 63, pp. 189-199.

Prefeitura de São Paulo, 2015. Geosampa.

http://geosampa.prefeitura.sp.gov.br/ (25 February 2018).

Prefeitura de São Paulo, 2011.

http://www.prefeitura.sp.gov.br/cidade/secretarias/urbanismo/da dos_estatisticos/index.php?p=160798 (25 February 2018).

Schaefers, T., 2013. Exploring carsharing usage motives: A hierarchical means-end chain analysis. Transportation Research Part A: Policy and Practice, 47, pp. 69-77.

Shaheen, S., 1999. Dynamics in Behavioral Adaptation to a Transportation Innovation: A Case Study of Carlink - A Smart Carsharing System. University of California, Berkeley.

Shaheen, S., Cohen, A., 2018. Shared Mobility Policies for California. UC Berkeley, Policy Briefs.

Shaheen, S., Cohen, A., Chung, M., 2009. North American carsharing: 10-year retrospective. Transportation Research Record, 2110, pp. 35-44.

Shaheen, S., Cohen, A., Zohdy, I., 2016. Shared mobility: Current practices and guiding principles. U.S. Department of Transportation, Federal Highway Administration.

Shaheen, S., Sperling, D., Wagner, C., 1998. Carsharing in Europe and North America: Past, Present and Future. University of California Transportation Center, UCTC n. 467.

Tully, C., Alfaraz, C., 2017. Youth and mobility: The lifestyle of the new generation as an indicator of a multi-local everyday life. Applied Mobilities, 2(2), pp. 182-198. 